\title{
Intestinal transplantation
}

\author{
Mine Ün ${ }^{1}(\mathbb{D}$, Oytun Erbaş²[D \\ ${ }^{1}$ Istanbul Aydin University Medical Faculty, Istanbul, Turkey \\ ${ }^{2}$ Department of Physiology, Demiroğlu Bilim University Faculty of Medicine, Istanbul, Turkey
}

\begin{abstract}
Although intestinal transplantation has become a standard in treating intestinal failure today, it has faced significant challenges up to this point. Intestinal transplantation, which is relatively more complicated and has higher likelihood of rejection compared to other solid organ transplantations such as the liver, kidneys, and heart, has gone a long way since the 1900s and has achieved successful results.

Keywords: Intestinal failure, intestinal transplantation, solid organ transplantation.
\end{abstract}

\section{INTESTINAL FAILURE AND ITS CAUSES}

Intestinal failure is the inability of the intestines in maintaining nutrient intake and fluid balance. $^{[1,2]}$ Although causes of intestinal failure vary between adult and pediatric populations, one of the most important causes is short bowel syndrome (SBS) (Figure 1). Short bowel syndrome is the removal of a portion of the small intestine for any reason and the insufficiency of the remaining small intestine for the person's nutrition and survival. Short bowel syndrome, tumors, and atresia lead to intestinal failure due to intestinal loss. ${ }^{[2]}$ Other causes of intestinal failure without intestinal loss are mucosal enteropathies and motility disorders. ${ }^{[2]}$

Sufficient absorption cannot occur after intestine loss. The minimum length of intestine required for sufficient absorption is not clearly defined. Various studies have proposed that the intestine must be a minimum length of $40 \mathrm{~cm} \cdot{ }^{[3,4]}$ Intestinal length shorter than $100 \mathrm{~cm}$ in the first year of life is considered abnormal..$^{[2,5-7]}$
Studies have reported that intestinal resection of up to $80 \%$ would be able to sustain life..$^{[8]}$

\section{INTESTINAL TRANSPLANTATION STUDIES}

Excessive colonization of microorganisms in the intestine makes intestinal transplantation more difficult than other solid organs. There is greater risk for tissue rejection and sepsis..$^{[9,10]}$ Therefore, survival rates of recipients are also lower compared to other organ transplantations. ${ }^{[11,12]}$

Intestinal transplantation was first attempted in 1959 by Lillehei et al. ${ }^{[13,14]}$ on dogs. Between 1964 and 1987, there were many interventions for transplantation of only the small intestine or both the small intestine and liver. ${ }^{[15]}$ Almost all attempts resulted in sepsis and failure due to surgical problems. ${ }^{[16]}$

In 1987, clinical practices followed comprehensive studies on pig intestines. ${ }^{[17]}$ One of the first clinical procedures on intestinal transplantation was performed in 1987 in Europe on a child with SBS. ${ }^{[18,19]}$ From 1987 to 1990, 

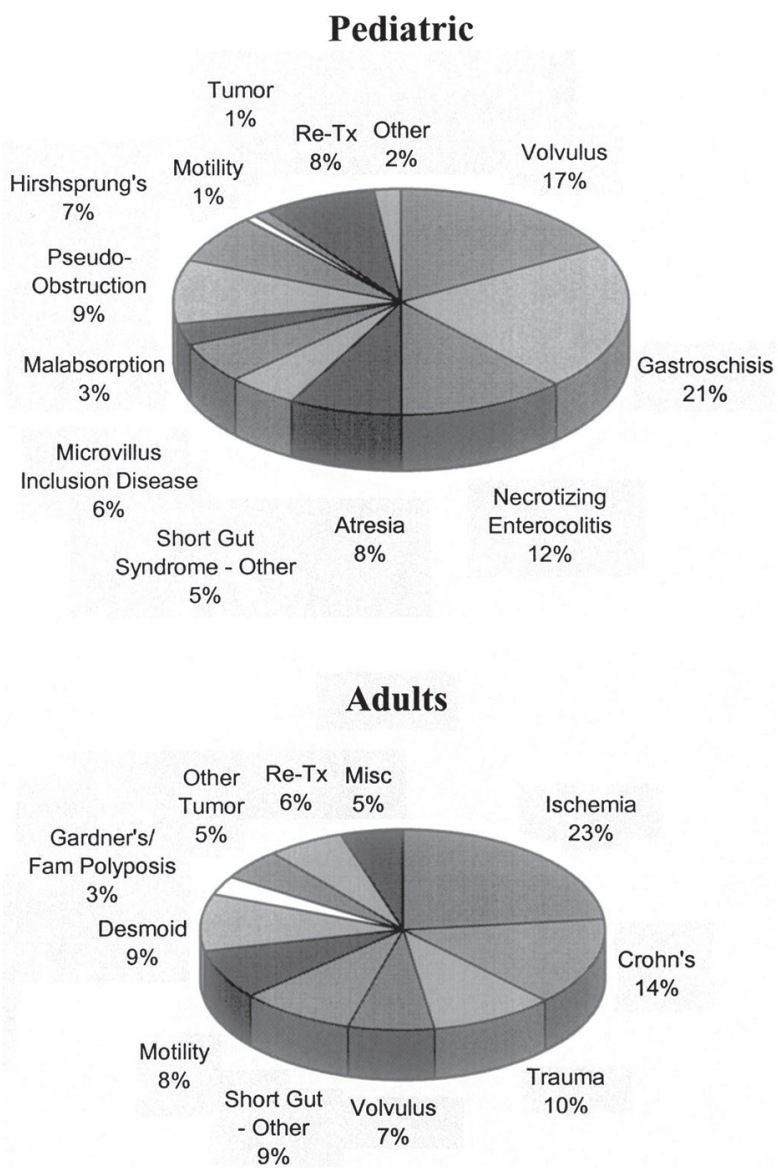

Figure 1. Causes of intestinal failure in adults and the pediatric population; Diseases such as gastroschisis, volvulus, necrotizing enterocolitis, atresia and short bowel syndrome are the most important causes of pediatric intestinal failure, while ischemia, Crohn's disease, traumas and desmoid diseases are the most important causes of adult intestinal failure. ${ }^{[9]}$

small intestine transplantation was conducted on nine children who were administered cyclosporin in France (Cyclosporin is an oral immunosuppressive calcineurin inhibitor). ${ }^{[20]}$ Only one of the nine patients had successful results. ${ }^{[18,19]}$ Until 1990, only two successful results, one in France and one in Germany, were achieved. ${ }^{[21,22]}$

One of the most important causes of low success rates of transplantations during this period was the lack of developments in immunosuppressive drugs. Since the immune system was not suppressed, organ rejection developed. While success rate of intestinal transplantations was low, there have been significant developments in intestinal transplantation interventions. ${ }^{[18,19]}$ The modern age of intestinal transplantation began in the 1990s in the United States. ${ }^{[23]}$

With the commercialization of tacrolimus in 1994, intestinal transplantation underwent developments worldwide. ${ }^{[18]}$ Tacrolimus is an immunosuppressive drug that reduces the threat of rejection following organ transplantation. ${ }^{[24]}$ Between 1994-2014, over 110 transplantations were performed in France. The annual number of intestinal transplantations is indicated below (Figure 2). ${ }^{[25]}$ Of these 110 transplantations, 36 patients had SBS, 30 intestinal motility disorders, and 34 congenital enteropathies. ${ }^{[25]} \mathrm{A}$ portion of these recipients underwent transplantation of only the small intestine, while others were transplanted both small and large intestines. Additionally, nine of the recipients also received liver transplantations together with intestinal transplantation due to liver failure secondary to intestinal failure. ${ }^{[25]}$

In the first week following transplantation, recipients were fed through an enteral tube, continued with parenteral nutrition after the second week, and were allowed to be fed orally after the first month. Recipients were gradually given lactose, fiber, and proteins. ${ }^{[25]}$ Within the first 10 months, intestines had to be removed in 28 recipients despite induction therapy. Ten patients underwent repeated transplantation. Only one patient achieved complete bowel functions, the others were lost due to organ rejection and sepsis. ${ }^{[19,26-28]}$

Evaluation of 101 children who underwent transplantation between 1994-2014 reported a survival rate of $33 \%$ in 2014. Deaths were due to multiorgan failure in $35 \%$ and liver failure in $50 \%$ of patients. A portion of the patients were lost due to bacterial and fungal sepsis (Enterobacter in three patients, Klebsiella in three patients, Proteus in one patient, Haemophilus in one patient and Aspergillus in two patients). Infections are a significant cause of death in these patients. ${ }^{[25,29-31]}$

\section{WHY IS THE LIVER TRANSPLANTED TOGETHER WITH THE SMALL INTESTINE?}

Patients with intestinal failure are fed with parenteral nutrition (delivery of the necessary 


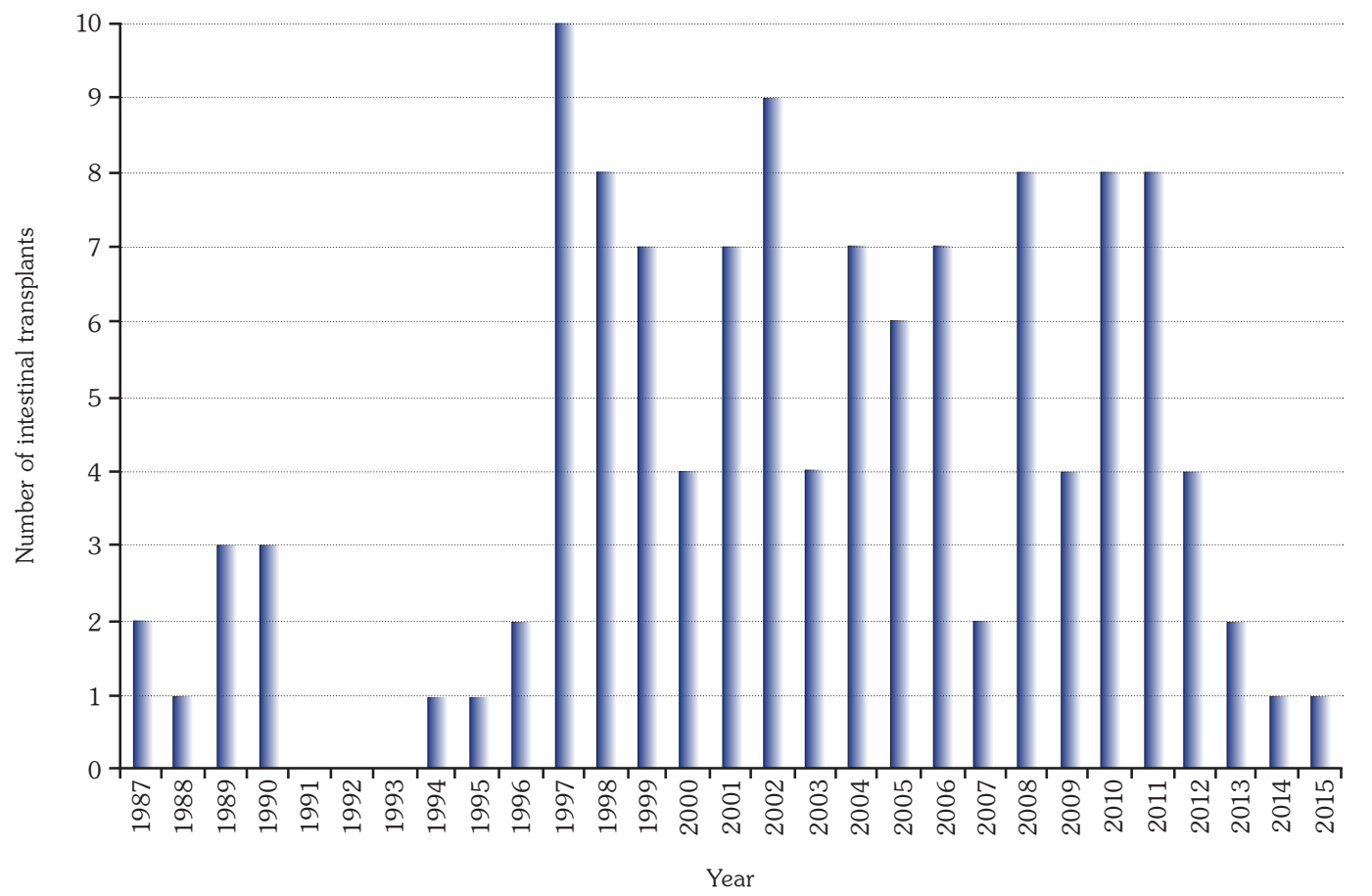

Figure 2. Annual number of intestinal transplantations. ${ }^{[25]}$

nutrients through intravenous feeding, when nutrients cannot be fully absorbed by the intestines). ${ }^{[32]}$ These patients develop liver failure due to parenteral nutrition. In this case, liver transplantation is conducted at the same time as the small intestine. ${ }^{[33]}$

\section{VASCULAR CONNECTIONS IN INTESTINAL TRANSPLANTATION}

The small intestine of the recipient is removed by cutting the Treitz ligament, revealing the veins and arteries. ${ }^{[16]}$ The intestine is transplanted with anastomoses of the recipient's infrarenal aorta and the superior mesenteric artery of the donor, and the inferior vena cava of the recipient and the superior mesenteric vein of the donor. An iliac artery is inserted between the aorta and the mesenteric artery and an iliac vein between the vena cava and the mesenteric vein to facilitate anastomosis and lengthen the mesenteric vessels (Figure 3). ${ }^{[25,34]}$ After vascular anastomosis is completed, it is checked whether or not blood is able to reach the organs. ${ }^{[16]}$

\section{CAN CHRONIC REJECTION BE PREVENTED AFTER INTESTINAL TRANSPLANTATION?}

Chronic rejection is the main problem in solid organ transplantations and occurs in 10\% of recipients of intestinal transplantations. No pharmacological approach has proven to be effective in preventing chronic rejection. Currently, the only solution in this case is to remove the transplanted intestine. ${ }^{[35]}$

According to the results of studies and archive reports, the inclusion of liver transplantation in intestinal transplantation is the only intervention that prevents chronic rejection. ${ }^{[35]}$

Studies have found that the necessary immunosuppression for liver transplantation is relatively lower compared to other transplants. Most of the patients with longterm survival are those who have underwent intestinal transplantation accompanied by liver transplantation. Therefore, it is believed that intestinal transplantation should also include liver transplant. The "liver effect" should be benefited from to prevent rejection. ${ }^{[30,36-39]}$ 


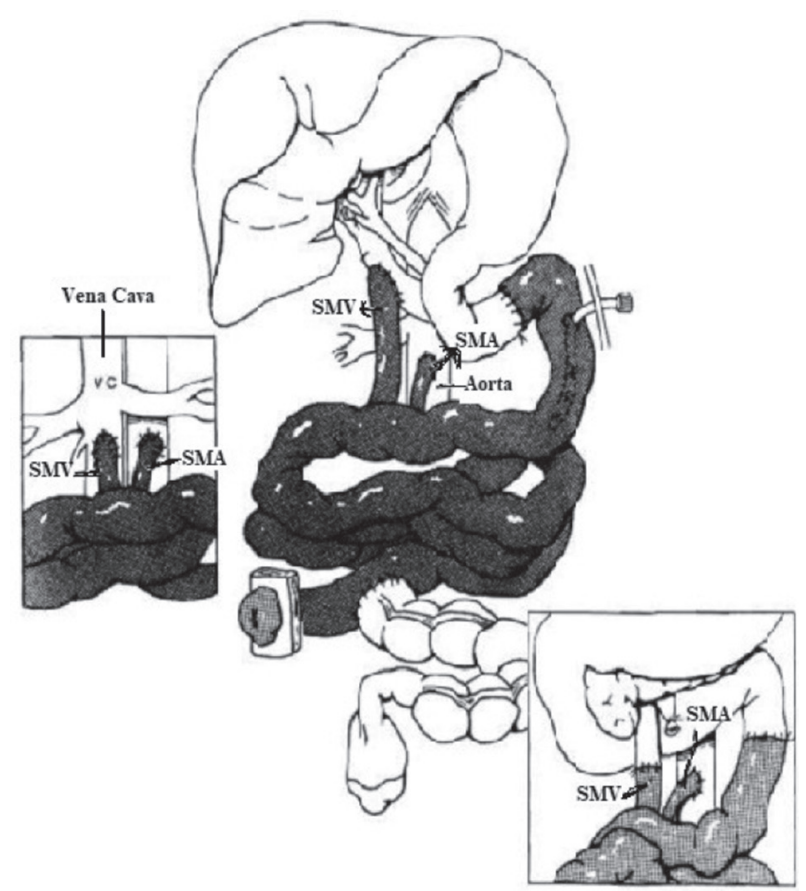

Figure 3. Anastomosis of the recipient's infrarenal aorta and the donor's superior mesenteric artery, and anastomosis of the donor's superior mesenteric vein with the inferior vena cava of the donor are shown. SMV: Superior mesenteric vein; SMA: Superior mesenteric artery. ${ }^{[34]}$

\section{HOW ARE DONORS SELECTED?}

The donor's ABO group should be the same as the recipient. Donors compatible for liver donation should also be compatible for small intestine donation. The donor should have the same or smaller size as the donor, since the volume of peritoneum cavity is usually decreased. ${ }^{[16]}$

Selective bacterial and fungal decontamination should be carried out. In other words, microorganisms in the donor should be identified and intravenous microorganismspecific antibiotic therapy should be applied to the recipient to prevent harm. Intestinal decontamination continues for at least six weeks after surgery and should be reinitiated in the periods of rejection. ${ }^{[16]}$

\section{RECIPIENTS AFTER INTESTINAL TRANSPLANTATION}

Looking back at the history of recipients 10 years after transplantations has shown many psychosocial problems including behavioral problems, developmental delay, cognitive ability disorders, school problems, anxiety, depression, and continuous reluctance to eat. ${ }^{[16]}$

Reluctance to eat is more common in children. This is because most children have never learned how to eat or have forgotten. This is why, despite lack of nutritional benefit, children are encouraged to eat before transplantation. ${ }^{[16]}$

According to studies, $46.6 \%$ of recipients attend personalized educational programs and social therapies. ${ }^{[40]}$

\section{STATISTICAL ANALYSIS OF INTESTINAL TRANSPLANTATION}

According to the 2003 report, a total of 989 transplantations were performed until that time. Reportedly, $61 \%$ of the recipients were under the age of $18 .{ }^{[9]}$ Until 2003, 75.5\% of the transplantations were performed in the USA, 19.1\% Europe, 1.4\% Asia, and 4\% in Canada, South and Central America, and the Middle East. ${ }^{[9]}$

According to the 2015 report, the number of intestinal transplants since 2007 had decreased due to high morbidity and mortality of the recipients. ${ }^{[26,41]}$ In 2015, The Intestinal Transplant Registry (ITR) had records of 1,697 children, in which half were still alive. ${ }^{[19,42]}$

According to the 2018 report, intestinal transplantation had undergone many developments since its start. In the last 10 years, with surgical developments, increased success in providing immunosuppression, and advancements in rehabilitation methods, there has been a significant increase in patient survival and decrease in morbidity. Patient survival has increased from $48.5 \%$ to $61.7 \%$ in the last decade (2007-2017). ${ }^{[40]}$

In conclusion, intestinal transplantation, which is relatively more complicated and has higher likelihood of rejection compared to other solid organ transplantations such as the liver, kidneys, and heart, has gone a long way since the 1900s and has achieved successful results; ${ }^{[43]}$ however, multicenter studies on immunosuppression and microbiota are needed to increase the success rate and patient survival. ${ }^{[25]}$

\section{Declaration of conflicting interests}

The authors declared no conflicts of interest with respect to the authorship and/or publication of this article. 


\section{Funding}

The authors received no financial support for the research and/or authorship of this article.

\section{REFERENCES}

1. Purdum PP 3rd, Kirby DF. Short-bowel syndrome: a review of the role of nutrition support. JPEN J Parenter Enteral Nutr 1991;15:93-101.

2. Çelik A. Bağırsak yetmezliği/kısa bağırsak sendromunda transplant dişı cerrahi yaklaşımlar. Çocuk Cerrahisi Dergisi 2017;31:56-76.

3. Grosfeld JL, Rescorla FJ, West KW. Short bowel syndrome in infancy and childhood. Analysis of survival in 60 patients. Am J Surg 1986;151:41-6.

4. Wilmore DW. Factors correlating with a successful outcome following extensive intestinal resection in newborn infants. J Pediatr 1972;80:88-95.

5. Sigalet D, Boctor D, Brindle M, Lam V, Robertson M. Elements of successful intestinal rehabilitation. J Pediatr Surg 2011;46:150-6.

6. Khalil BA, Ba'ath ME, Aziz A, Forsythe L, Gozzini $\mathrm{S}$, Murphy $\mathrm{F}$, et al. Intestinal rehabilitation and bowel reconstructive surgery: improved outcomes in children with short bowel syndrome. J Pediatr Gastroenterol Nutr 2012;54:505-9.

7. Soden JS. Clinical assessment of the child with intestinal failure. Semin Pediatr Surg 2010;19:10-9.

8. Flint JM. The effect of extensive resection of the small intestine. Bull johns Hopkins Hosp 1912;23:127-44.

9. Grant D, Abu-Elmagd K, Reyes J, Tzakis A, Langnas A, Fishbein T, et al. 2003 report of the intestine transplant registry: a new era has dawned. Ann Surg 2005;241:607-13.

10. Newell KA. Transplantation of the intestine: is it truly different? Am J Transplant 2003;3:1-2.

11. Grant D. Current results of intestinal transplantation. The International Intestinal Transplant Registry. Lancet 1996;347:1801-3.

12. Grant D. Intestinal transplantation: 1997 report of the international registry. Intestinal Transplant Registry. Transplantation 1999;67:1061-4.

13. Lillehei RC, Goott B, Miller FA. The physiological response of the small bowel of the dog to ischemia including prolonged in vitro preservation of the bowel with successful replacement and survival. Ann Surg 1959; 150:543-60.

14. Lillehei RC, Idezuki Y, Feemster JA, Dietzman RH, Kelly WD, Merkel FK, et al. Transplantation of stomach, intestine, and pancreas: experimental and clinical observations. Surgery 1967;62:721-41.

15. Grant D. Intestinal transplantation: current status. Transplant Proc 1989;21:2869-71.

16. Reyes J, Tzakis AG, Todo S, Nour B, Starzl TE. Small bowel and liver/small bowel transplantation in children. Semin Pediatr Surg 1993;2:289-300.

17. Ricour C, Revillon Y, Pletyncx M, Laufenburger A,
JehanninB, GhnassiaD, etal. Hypothermic conservation and autotransplantation of small intestine in piglets (author's transl). Gastroenterol Clin Biol 1981;5:97786.

18. Pritchard TJ, Kirkman RL. Small bowel transplantation. World J Surg 1985;9:860-7.

19. Intestinal Transplant Registry. Available at: http:// www.intestinaltransplant.org

20. Onsun N. Siklosporin. Turkderm - Arch Turk Dermatol Venerology 2016;50:26-8.

21. Goulet O, Révillon Y, Jan D, Brousse N, De Potter S, Cerf-Bensussan N, et al. Small-bowel transplantation in children. Transplant Proc 1990;22:2499-500.

22. Deltz E, Schroeder P, Gebhardt H. Successful clinical small bowel transplantation: Report of a case. Clin Transplant 1989;3:89.

23. Dickinson DM, Arrington CJ, Fant G, Levine GN, Schaubel DE, Pruett TL, et al. SRTR program-specific reports on outcomes: a guide for the new reader. Am J Transplant 2008;8:1012-26.

24. Wu Q, Marescaux C, Wolff V, Jeung MY, Kessler $\mathrm{R}$, Lauer $\mathrm{V}$, et al. Tacrolimus-associated posterior reversible encephalopathy syndrome after solid organ transplantation. Eur Neurol 2010;64:169-77.

25. Lacaille F, Irtan S, Dupic L, Talbotec C, Lesage F, Colomb V, et al. Twenty-eight years of intestinal transplantation in Paris: experience of the oldest European center. Transpl Int 2017;30:178-86.

26. DeLegge M, Alsolaiman MM, Barbour E, Bassas S, Siddiqi MF, Moore NM. Short bowel syndrome: parenteral nutrition versus intestinal transplantation. Where are we today? Dig Dis Sci 2007;52:876-92.

27. Girard M, Lacaille F, Verkarre V, Mategot R, Feldmann G, Grodet A, et al. MYO5B and bile salt export pump contribute to cholestatic liver disorder in microvillous inclusion disease. Hepatology 2014;60:301-10.

28. D'Antiga L, Goulet O. Intestinal failure in children: the European view. J Pediatr Gastroenterol Nutr 2013;56:118-26.

29. Loinaz C, Kato T, Nishida S, Weppler D, Levi D, Dowdy L, et al. Bacterial infections after intestine and multivisceral transplantation. The experience of the University of Miami (1994-2001). Hepatogastroenterology 2006;53:234-42.

30. Abu-Elmagd KM, Costa G, Bond GJ, Soltys K, Sindhi $\mathrm{R}, \mathrm{Wu}$ T, Koritsky DA, et al. Five hundred intestinal and multivisceral transplantations at a single center: major advances with new challenges. Ann Surg 2009;250:567-81.

31. Karthaus M. Prophylaxis and treatment of invasive aspergillosis with voriconazole, posaconazole and caspofungin: review of the literature. Eur J Med Res 2011;16:145-52.

32. Usta Y. Parenteral Beslenme. Turkiye Klinikleri J Pediatr Sci 2017;13:178-88.

33. Sudan DL, Iyer KR, Deroover A, Chinnakotla S, Fox IJ Jr, Shaw BW Jr, et al. A new technique 
for combined liver/small intestinal transplantation. Transplantation 2001;72:1846-8.

34. Reyes J, Tzakis AG, Todo S, Nour B, Starzl TE. Small bowel and liver/small bowel transplantation in children. Semin Pediatr Surg 1993;2:289-300.

35. Lauro A, Oltean M, Marino IR. Chronic rejection after intestinal transplant: where are we in order to avert it? Dig Dis Sci 2018;63:551-562.

36. Kato T, Tzakis AG, Selvaggi G, Gaynor JJ, David AI, Bussotti A, et al. Intestinal and multivisceral transplantation in children. Ann Surg 2006;243:756-64.

37. Sarnacki S, Révillon Y, Cerf-Bensussan N, Calise $\mathrm{D}$, Goulet $\mathrm{O}$, Brousse N. Long-term small-bowel graft survival induced by a spontaneously tolerated liver allograft in inbred rat strains. Transplantation 1992;54:383-5.
38. Jugie M, Canioni D, Le Bihan C, Sarnacki S, Revillon Y, Jan D, et al. Study of the impact of liver transplantation on the outcome of intestinal grafts in children. Transplantation 2006;81:992-7.

39. Wu G, Cruz RJ. Liver inclusion improves outcomes of intestinal retransplantation in adults. [Corrected]. Transplantation 2015;99:1265-72.

40. Celik N, Stanley K, Rudolph J, Al-Issa F, Kosmach $\mathrm{B}$, Ashokkumar $\mathrm{C}$, et al. Improvements in intestine transplantation. Semin Pediatr Surg 2018;27:267-72.

41. Goulet O. Intestinal failure, parenteral nutrition and liver disease. Pediatr Adolescent Med 2012;16:175.

42. Grant D, Abu-Elmagd K, Mazariegos G, Vianna R, Langnas A, Mangus $R$, et al. Intestinal transplant registry report: global activity and trends. Am J Transplant 2015;15:210-9.

43. Kapan SE, Kapan M. İnce bağırsak transplantasyonu. Turkiye Klinikleri J Surg Med Sci 2005;1:70-2. 